\title{
VIRTUAL RESTITUTION OF THE PARIETAL DECORATION IN THE SALA DEL MOSAICO DE LOS AMORES. CASTULO ARCHAEOLOGICAL SITE (LINARES, SPAIN)
}

\author{
T. López-Martínez ${ }^{1 *}$, B. Calvo-Bartolomé ${ }^{2}$, A. García-Bueno ${ }^{1}$ \\ ${ }^{1}$ Department of Painting, University of Granada, Granada, Spain - tlopez@ugr.es, anagar@ugr.es \\ ${ }^{2}$ San Fernando Royal Academy of Fine Arts, Madrid, Spain - b.triz.calvo@gmail.com
}

KEY WORDS: Virtual restitution, restoration, archaeological wall painting, 3D, photogrammetry.

\begin{abstract}
:
The use of photogrammetry in the field of archaeology is increasingly widespread. In the case of restoration, the use of 3D contributes to facilitating the complex process of an intervention and bringing the artwork closer to the general public. This paper describes the application of 3D modelling techniques in the specific case of the Roman wall paintings from the Sala del Mosaico de los Amores, in Castulo Archaeological Site (Linares, province of Jaén). These paintings were found in 2011, collapsed over the mosaic pavement, and they were moved to the University of Granada for their restoration. After the intervention, the photogrammetric surveys of the different fragments and of the room to which they belong were developed, and the virtual restitution was generated, therefore making it possible for the general public to reliably appreciate how the room would look like with the parietal decoration located in-situ.
\end{abstract}

\section{INTRODUCTION}

In recent years, the development of new technologies and their resulting accessibility have fostered their inclusion in different fields, such as cultural heritage. Even though the digitisation of images and the 3D reproduction and modelling techniques such as photogrammetry were considered as an end in themselves, nowadays the intention is for them to be: on the one hand, tools to facilitate the conservation and restoration of cultural heritage and, on the other hand, tools for the dissemination of that heritage.

There are different examples of the first case, that is, using 3D to facilitate the restoration works of an artwork. One of them is the Madonna di Pietranico, in which new technologies were used to study the possibilities to join the fragments, to design and produce a structure to support them and, finally, to virtually study and restore the polychrome decoration of the artwork (Arbace et al., 2013). Another example is the use of photogrammetry for the assessment of cleaning treatments, as it serves to choose the most suitable treatment to be applied in the intervention of the artwork (López-Martínez et al., 2018).

In the second case, their use as dissemination tools, they have offered a special advantage in the specific case of archaeological heritage, as the criterion that currently prevails in most cases is the one of minimum intervention. This makes it very difficult for non-specialist public to understand this kind of heritage in its entirely. In these occasions, the possibilities offered by digital techniques enormously facilitate the task of bringing artworks closer to society. An example of this is the case presented in this paper, that case of the wall paintings of Castulo Archaeological Site.

\section{RESTORATION OF THE WALL PAINTINGS IN CASTULO}

The excavations in the Iberian-Roman site of Castulo were resumed in 2011, after it was declared Archaeological Site. During the excavations, a public building of approximately $33 \times 12 \mathrm{~m}$ was discovered. It was erected, apparently, in honour of the emperor Domiciano, and consists of several rooms with mosaics and wall paintings, being the Room 1 or Sala del Mosaico de los Amores the one that stands out. The wall paintings corresponding to the West wall were found collapsed, covering the mosaic pavement (Figure 1) (Jiménez Morillas, 2014). These wall coverings were moved to the wall painting restoration laboratory of the University of Granada for their restoration (López-Martínez, et. al., 2016).

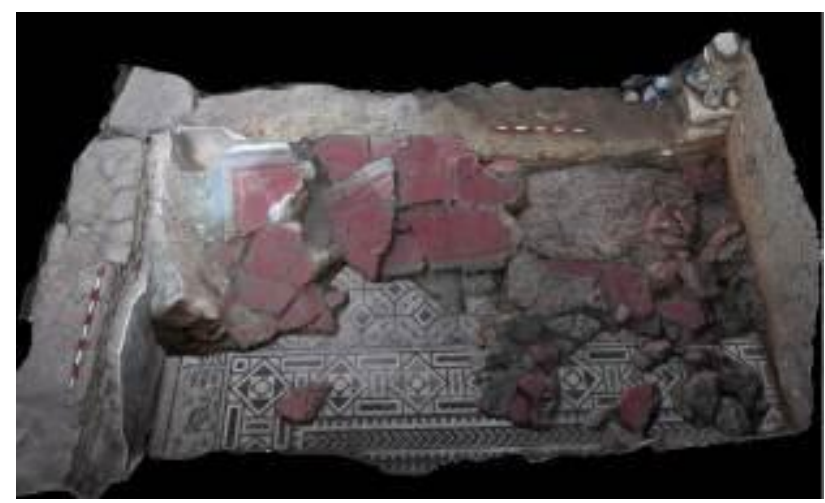

Figure 1. Collapse of the wall coverings in the Sala del Mosaico de los Amores (López Rodriguez, 2014).

\footnotetext{
* Corresponding author
} 
After they had been moved, an extensive photographic documentation was carried out, the fragments were cleaned and consolidated and afterwards joined together. However, they were left at an intermediate stage of restoration until the intervention of the whole wall is finished. At this point, it will be possible to join everything together and proceed to their insitu restitution.

For this reason, the public visiting the archaeological site nowadays can only see the mosaic decoration and a metallic support in the place in which the parietal decoration would be placed (Figure 2). A digital support offers the possibility of observing the virtual reconstruction made by the FORVM MMX team when documenting the collapse, which gives an idea of how the decorative scheme would look like. Nevertheless, the small specific details or the qualities of the wall coverings cannot be appreciated; on the contrary, they can be better perceived with a photographic texture.

This is the reason that led to the thought that a virtual restitution through the photogrammetric digitisation of both the room and the different fragments already restored would allow a better approach of the general public to this artwork. Likewise, this approach would help the artwork being better appreciated, therefore contributing to its conservation.

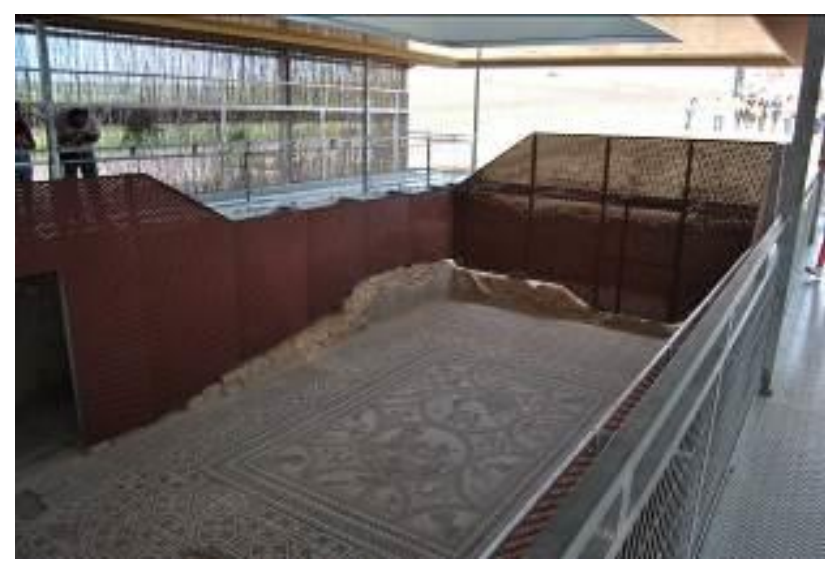

Figure 2. Current state of the Sala del Mosaico de los Amores

\section{VIRTUAL RESTITUTION OF THE WALL COVERINGS}

\subsection{Photogrammetry}

The first step for the virtual restitution of the decoration was the digitisation process, of both the room and the restored fragments. Such process was carried out using photogrammetry.

Firstly, we carried out the photographic documentation of the West wall to which the restored fragments belong.

The photographic record of the West wall and part of the mosaic was made using a Nikon D5300 reflex camera with a vari-angle monitor and AF-S Nikkor $18-105 \mathrm{~mm}$ VR lens. The shooting consisted of 175 photographs, perpendicular to the surface and covering the whole surface being documented. The photographs were required to have a minimum overlap of $60 \%$ and to be positioned at a fixed focal length. Besides, even though the room is covered, it always has natural light; therefore, when taking the photographs, we tried to maintain constant lighting conditions in the area being documented, in order to avoid very pronounced shades.

On the contrary, the digitisation of fragments was performed in the laboratory, making it easier to control the lighting conditions. For the photographic session, those fragments which are adjoining were placed close to each other, documenting them by groups. Thanks to this, the number of photogrammetric models generated was reduced, therefore facilitating the subsequent work.

The photographic shooting was conducted with the aforementioned camera, taking into account the same aspects. Additionally, a scale was placed next to the fragments being digitised for the correct measurement of the models.

The homogeneous lighting conditions during the data collection allowed to economise pre-processes and save time. These preprocesses, which are aimed at correcting the lights and shades of the photographs, are usually made with shots in RAW and Photoshop software, which allows the improvement of the visual quality with a view to a cleaner $3 \mathrm{D}$ processing. Nevertheless, the work in this case was minimal, helping to optimise working times, which is a very important factor in $3 \mathrm{D}$ modelling processes.

Each of the four wall painting fragments as well as the model of the room were processed separately, using Agisoft software, always following the exact same steps and using the same parameters.

The photographs were taken using a "movable station" instead of a "fixed station". This later option, which requires that the object rotates while the camera remains static, would have made it necessary to apply "masks", that is, to remove the background of each photograph, therefore entailing extra work time. On the contrary, the first option, allowed to directly proceed with the first step of the process.

The photographs, varying from 70 and 100 shots depending on the fragments, were loaded in the software. After that, we proceeded to the first step of the obtention of a sparse point cloud, with the following parameter configuration:

Quality: maximum. Tie points between pictures: 9.000. Key points limit: 90.000

To ensure that everything was processed in high-quality, the system was equipped with $32 \mathrm{~GB}$ RAM and a quad-core Intel Core i5 processor at $3.4 \mathrm{GHz}$. Therefore, waiting time between the different processing steps was reduce and better geometric and visual results were achieved.

After the first image pairing (the one in which the software finds equivalent point pairs and locates them in the virtual space, referencing each other and creating an internal coordinate system) the sparse point cloud was built. It was correctly oriented and aligned, and those points which did not correspond to the fragment but to the background were removed. Thanks to this cleaning, the following step was quicker.

Building the dense point cloud can take a few hours, depending on the system being used, the number of photographs and the quality of the previous point cloud. After the processing is finished, the point cloud is so dense that it is possible to anticipate how the final result would look like, as it is made 
with colour points (Figure 3). The models shown in this paper gave as a result an average of 17 million points. That is a high figure which ensured good results without risks, achieved by means of high-quality processing and a moderate depth filtering mode (probably the most widely used). A second cleaning, much more thorough and manually carried out, must always be made. The model must be effectively cleaned of points, most of the generated by lights, shines and support devices. Even though the software includes automatic tools which allow the selection of colour points, for example, so that they can all be removed at the same time, truth is that automatic tools do not always provide the results needed. It was necessary in all cases to manually remove those points; a task which required time and patience, but which finally gave outstanding results.

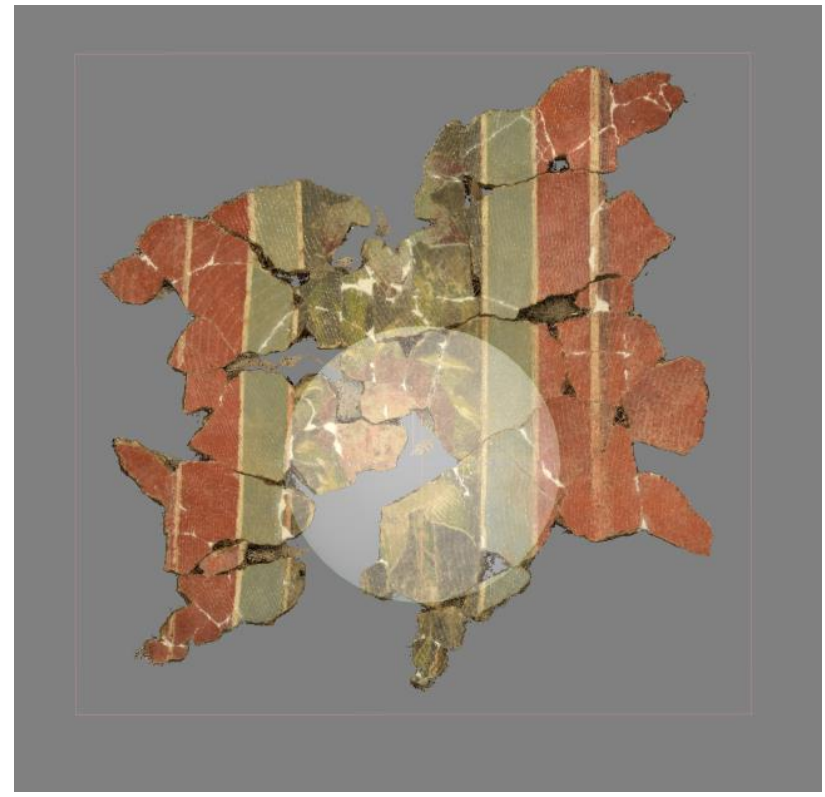

Figure 3. Dense point cloud of one of the fragments from the interpanels.

The third step was generating the geometry on the basis of the "dense cloud" and by creating triangles, with a quality which gave an average of 3.5 million faces and always using the point interpolation function, which covers holes or areas with lower density of points, generating those that could not be created in the previous step. The processing time for this step was 20 minutes in almost all cases.

Then, the photorealistic texture of the photographs was added to the virtual geometry. Generated in $6 \mathrm{~K}$ quality, it was sufficiently defined and allowed to enlarge the object as much as desired. This was, without a hint of a doubt, the quickest step, taking no longer than 10 minutes.

All the previous steps and experience were important to be taken into account, as the work to be carried out after the shooting would be easier if simple aspects were considered, aspects so simple as ensuring that all photographs were equally oriented so that the software would recognise them properly and would not incorrectly pair them. Likewise, it was important that the lighting conditions and colours were homogeneous and faithful to the object; as even though the software makes an average, or intermediate colour, of all the points appearing in the photograph when building the texture, they could entail the appearance of incorrect colours which, in the case of the painting, would lead to a serious mistake for the scientific research. For this reason, the camera must always be properly calibrated.

\subsection{Retopology}

Once the fragments and the room were digitised, it was necessary to address difficult task of joining them together and placing them in the same workspace. The fact that each model had an average of 3.5 million faces complicated even tasks as simple as loading them at the same time. Therefore, moving them to position them correctly would have been impossible, despite the quite powerful system being used.

At this stage, we had to reconsider the processes and include an intermediate step which would enable to work with very light models, which is why we resorted to retopology.

The technology of videogames and animations is quite frequently very far ahead of those techniques used in heritage. Therefore, from time to time it is advisable to search for new tools which can help in the different tasks: study, dissemination, conservation, etc. That is the case of retopology, born from virtual sculpting, which makes it possible to reduce models containing million faces to roughly two or three thousand faces (a figure which could increase depending on the geometric complexity of the model) at the same time that the quality is maintained. In this case, the models were not very complex from a geometrical point of view, therefore it was possible to generate very light pieces which were easy to work with.

The basis for the creation of a "low poly" model, or transformation of a 3D scanning in "low poly", is the creation of a second topology or second skin, very simplified and light, to which all visual information in terms of geometry and texture is transferred.

Even though retopology offers automatic tools such as Instant Meshes, sometimes the finishes are not the desired ones and they need to be manually retouched. This automatism generates confusing meshes, particularly in those areas of difficult geometry such as edges or gaps, so the manual retouching could take too much time. At this point, we assessed which option, whether automatic or manual retopology, allowed us to reduce more time and improvee the quality of the mesh. We made a light mesh of the room with Instant Meshes software. It had to be retouched with Blender in several points, and the result was a high quantity of time devoted to this process and a mesh of a quality that could be improved. Taking into account the simplicity of the rest of the models, we decided that making the manual retopology with Blender was going to optimise working time and provide the desired quality, therefore this last option was chosen. As can be deduced, only free software was used. We needed to consider the budget and determine to which extent it was worthwhile to acquire programmes which allowed automatic retopologies of good quality but whose prices were expensive.

It was quite simple to create a mesh which adjusted to the model built. This new geometry was to be based in quads, much simpler than the original meshes consisting of triangles. Therefore, they would not have the same quality as the original mesh due to their simplicity. Once this second model was built, it had to be "cut" in islands to make the mapping. This mapping was essential in order to transfer all information and quality, 
from the point of view of both the geometry and the texture (Figure 4). Once the chunks in which we divided the figure were organised, the figure was given a material (of which it lacked so far) and, in the work screen, an empty texture was added using nodes. This empty texture was the one to which the information would be transferred. The first step in each piece was creating the normal map; these normals make reference to the place where each polygon is located in the virtual space, mutually referenced and joined, creating the geometry itself. Therefore, each of the quads composing the "low poly" contains visual information on hundreds or thousands of faces of the original.

The second transfer done to each model was adding a photorealistic texture. For this purpose, a second empty image was generated, which would contain the texture positioned in the same way as the mappings were arranged. Therefore, there must be a total coincidence between the normal and the texture mappings. Building this second 3D model and its mappings would make it possible to publish them online, using 3D Sketchfab, or even embed the model in a website.

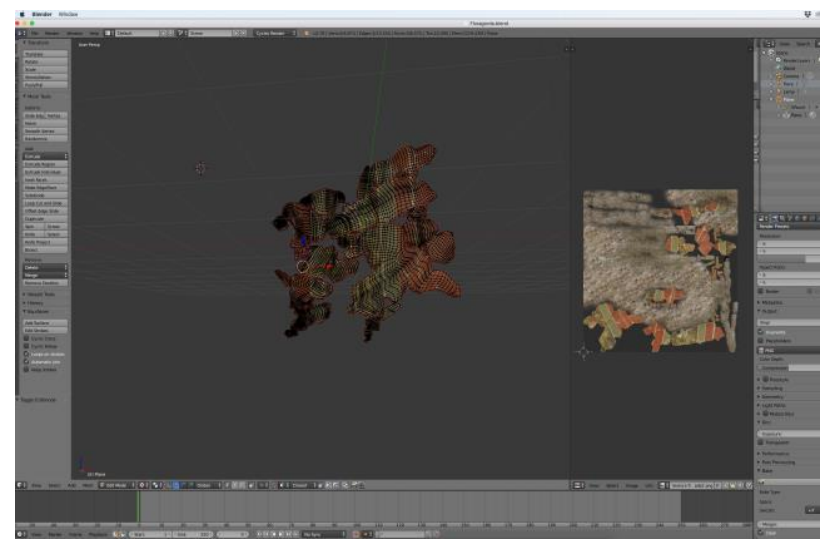

Figure 4. Retopology and texture mapping

\subsection{Positioning of fragments}

Once the retopology of the fragments and the room were built (as explained, a critical step to be able to work with all models in just one file), next procedure was arranging themselves and in relation to the room

Joining them together and correctly arranging them was achieved by orienting the models in the virtual space and providing them, and the room, with the correct proportions. Said proportion was virtually created using measurements of the programme itself which corresponded to centimetres in reality. The orientation was just a simple mathematical step in axes $\mathrm{X}$, $\mathrm{Y}$ and $\mathrm{Z}$. Arranging the fragments was, by far, the most manual process of all. It was based in the information provided by the archaeologists with the georeferencing of the fragments and in the configuration lines of the original design which composed the gammadions of the skirting, the dividing lines, the interpanels, etc. Likewise, we used orthogonal virtual elements as a grid, with the objective of obtaining the maximum possible accuracy.

In this way, same as it would have been made in a material restoration, each fragment was placed in relation to the wall painting which is still in-situ preserved in the room, in the skirting in this case. For this reason, those fragments being firstly arranged were those of the lower area, as the geometrical design allowed to exactly determine their location in relation to the model of the room. Once the fragments of the skirting were positioned, the two interpanels were placed. To do that, as previously stated, the georeferencing of the fragments provided by the team of archaeologists were taken as reference.

Finally, to achieve higher unity of the ensemble and better realism, as once again this is a criterion which would be fulfilled in a material restoration of the artwork, an intervention mortar was modelled with Blender. It was composed of all the restored fragments and integrated them in the ensemble of the room and the coatings still preserved in-situ. To do that, the model was built using polygons which were extruded until the required total surface was completed, giving a finish which would unite the fragments, reinforcing the weakest points (such as the edges of the fragments in the interpanels) but not interfering with the view or perception of the original fragments. For this reason, it was given the photographic texture of a mortar of very thin granulometry and light tones, which would not divert the attention from the original painting.

\subsection{Obtaining images for diffusion}

After finishing the complete model of the West wall of the room with the fragments restored and located in their corresponding position and the intervention mortar which unifies them, a postprocessing was carried out to obtain more realistic 2D images which would offer more information to the general public. This was achieved by rendering the model and subsequently processing the obtained images, making a virtual chromatic reintegration of the intervention mortar.

3.4.1 Rendering: It is the process of generating a realistic digital image from a 3D model, containing the material qualities of the object, the textures and the lights and shades applied. In this case, two lamps were used: one of them provided directional light, with white light and 2.500 power; the other provided point light, also with white light and 300.000 power. Finally, the camera was positioned in several places and different renders were obtained.

3.4.2 Reintegration using Photoshop: Once the rendered images were obtained, the next step was to make the chromatic reintegration of the intervention mortar, so that the compositional pattern could be better understood by the general public. To do that, we followed the archaeological criterion: applying flat inks in a tone which is lighter than the original and not reproducing neither the geometrical motifs nor the decoration of the interpanels of which no information was available. On the contrary, we marked the lines demarcating the interpanels and the skirting, as well as those framing the big red panels, as full information on them was available and they helped to reinforce the decorative scheme. (Figure 5).

\section{CONCLUSIONS}

This paper presents the virtual restitution of some fragments which have been already restored from the Sala del Mosaico de los Amores in Castulo Archaeological Site (Linares, province of Jaén, Spain).

The digitisation of the different fragments using photogrammetry together with the photogrammetric survey of 


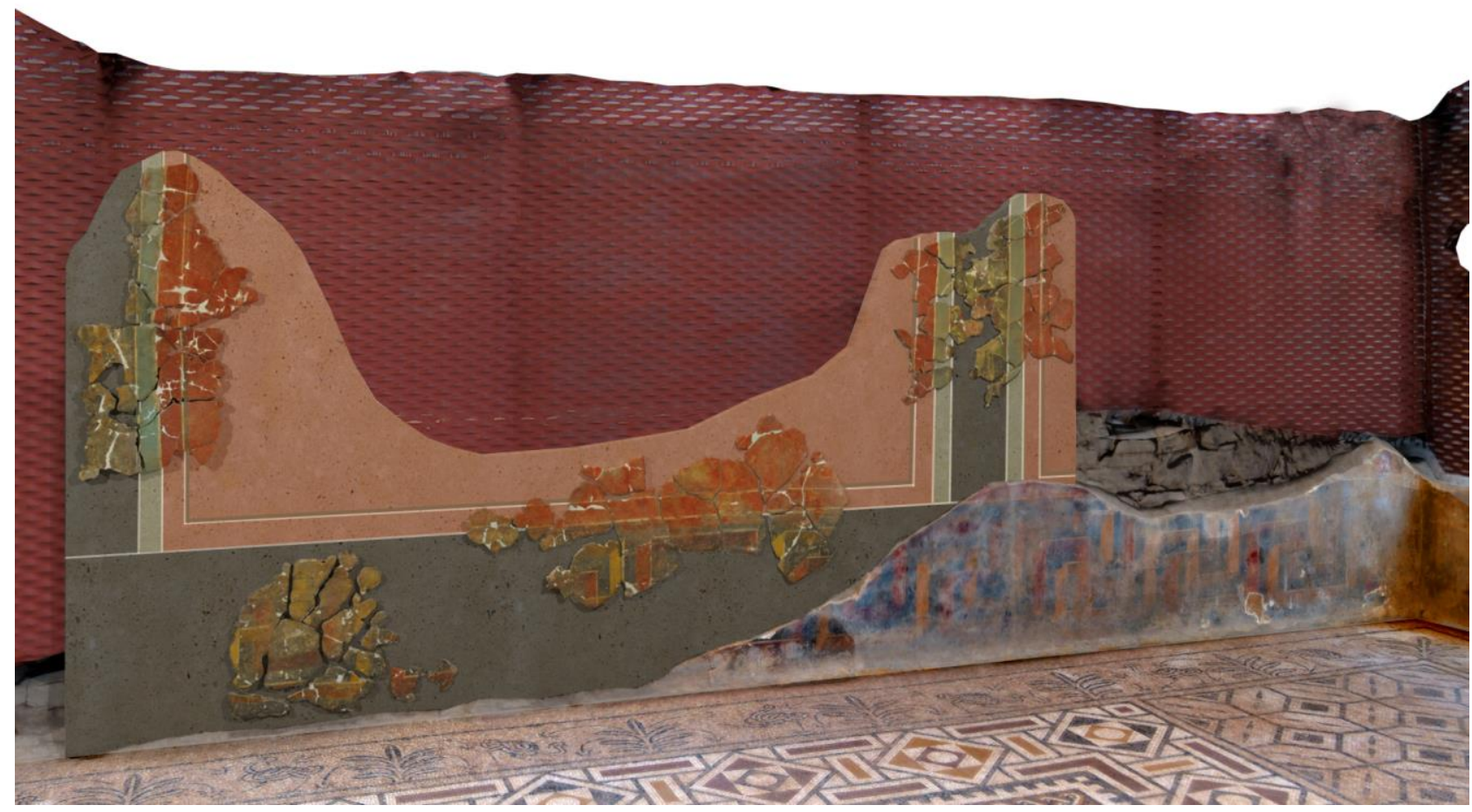

Figure 5. Final image rendered image of the room, including the chromatic reintegration of the intervention mortar.

the West wall of the room have allowed to show, in a much more attractive way, the current state of the fragments intervened. Likewise, the modelling of an intervention mortar and the virtual chromatic reintegration provide the public with a much more faithful and comprehensible image of the compositional pattern of the room, and the aspect it will enjoy after the restoration of the entire wall coating is finished and it is relocated in-situ.

It is demonstrated therefore that the use of $3 \mathrm{D}$ is increasingly present in the archaeology and restoration fields, enormously facilitating the dissemination of archaeological heritage, an aspect which is essential in the aim of rising awareness within society of its importance and, therefore, of the need of conserving and preserving heritage.

\section{ACKNOWLEDGEMENTS}

We would like to express our most sincere gratitude to the FORVM MMX Project, in particular to its director Marcelo Castro and its restorer $\mathrm{M}^{\mathrm{a}}$ Paz López, for allowing us and facilitating the study of the wall paintings of Castulo Archaeological Site. Likewise, to the San Fernando Royal Academy of Fine Arts, in particular to Itziar Arana, for allowing the collaboration between both institutions. This work has been funded by the Ministry of Economy and Competitiveness and by the European Regional Development Fund (MINECO/FEDER, UE) within the framework of the Research Project HAR2015-66139-P; as well as by the research project "Chromatic treatments in architecture of Islamic tradition. Techniques and Conservation" (P12 HUM 1941) by the Andalusian Regional Government, Department of Economy, Innovation, Science and Employment; and by the University Faculty Training Program (FPU) granted to one of the authors.

\section{REFERENCES}

Arbace, L., Sonnino, E., Callieri, M., Dellepiane, M., Fabbri, M., Idelson, A.I., Scopigno, R., 2013. Innovative uses of 3D digital technologies to assist the restoration of a fragmented terracotta statue. Journal of Cultural Heritage, 14, 332-345.

Jiménez Morillas, Y., 2014. El possible edificio del culto imperial. Una reflexión forzosamente penúltimal. 7 esquinas, 6 , 89-103.

López-Martínez, T., García-Bueno, A., Medina-Flórez, V.J., 2018. New methodology for the assessment of cleaning treatments. Applications of photogrammetry for restoration. Journal of Cultural Heritage, 30, 117-123.

López-Martinez, T., López Cruz, O., García Bueno, A., CaleroCastillo, A. I., Medina Flórez, V. J., 2016. Las pinturas murales de Castulo. Primeras aportaciones a la caracterización de materiales y técnicas de ejecución. Lucentum, 35, 155-170.

López Rodriguez, M.P., 2014. La experiencia en conservación preventiva del Conjunto Arqueológico de Cástulo. 7 esquinas, 6, 29-43. 